\title{
Dentin Exposure after Tooth Preparation for Porcelain Laminate Veneers: A Microscopical Analysis +
}

\author{
Fernando Zarone, Gennaro Ruggiero * and Roberto Sorrentino \\ Reproductive and Odontostomatological Sciences, University “Federico II" of Naples, 80131 Naples, Italy; \\ fernandozarone@mac.com (F.Z.); errestino@libero.it (R.S.) \\ * Correspondence: gennaro_ruggiero@hotmail.it; Tel.: +39-081-746-3018 \\ + Presented at 1st International Electronic Conference on Applied Sciences, 10-30 November 2020; \\ Available online: https://asec2020.sciforum.net/.
}

Published: 10 November 2020

\begin{abstract}
Background: To assess the quantity of exposed dentin detected by 3 operators for 2 different geometries of tooth preparations, window (WI) and butt-joint (BJ); Methods: 20 intact maxillary central incisors were collected. One prosthodontist prepared the specimens for porcelain laminate veneers to a depth of $0.6 \mathrm{~mm}$, with a cervical chamfer-line of $0.3 \mathrm{~mm}$, using a silicone index. Subsequently, each prepared tooth was analyzed by 3 operators with different clinical experience, student (ST), medium experienced (ME), and expert (EX) to calculate the percentage of exposed dentin at sight under magnification. In addition to descriptive statistics (CI 95\%), a 2-way ANOVA and the Games-Howell test were used to analyze differences among groups $(\alpha=0.05)$; Results: The means of the calculated percentages of dentin exposure were: $\mathrm{WI}=30.48 \%$; $\mathrm{BJ}=30.99 \%$; ST $/ \mathrm{WI}=$ $22.82 \%$; ME $/ \mathrm{WI}=58.05 \%$; $\mathrm{EX} / \mathrm{WI}=10.55 \% ; \mathrm{ST} / \mathrm{BJ}=28.99 \% ; \mathrm{ME} / \mathrm{BJ}=40.56 \% ; \mathrm{EX} / \mathrm{BJ}=23.42 \%$. The 2way ANOVA detected significant differences among operators $(p<0.001)$ but not between WI and BJ $(p=0.898)$. The Games-Howell test detected differences between ST/WI and ME/WI $(p=0.005)$ and between ME/WI and EX/WI $(p<0.001)$; Conclusion: There is no difference in the detection of exposed dentine among operators with different expertise for BJ preparation, whereas differences were detected between ME and the other 2 operators in the WI preparation.
\end{abstract}

Keywords: ceramic veneers; veneers; minimally invasive; tooth preparation

\section{Introduction}

The porcelain laminate veneer (PLV) is a thin ceramic restoration that restores the tooth at the incisal, facial and part of the interproximal surfaces, in order to improve its aesthetics [1].

Four tooth preparation geometries are used for PLV: window [2], feathered edge, butt joint and palatal chamfer $[3,4]$.

To date, it is not established if there is an association between these preparation geometries and the amount of dentin exposure.

Unfortunately, it is not easy to identify the dentin structure during the tooth preparation; therefore, to reduce the quantity of exposed dentin, magnification systems are often used to better visualize the dental tissue.

The purpose of the present in vitro study was to assess the quantity of dentin exposed through the use of a stereomicroscope at a magnification of $16 \times$ in 2 different tooth preparation geometries, window and butt joint.

Two null hypotheses were formulated: 
1. There is no association between the type of tooth preparation and the amount of dentin exposed;

2. There is no difference in the visual discrimination of the hard tissues of the tooth for operators with different clinical experience.

\section{Materials and Methods}

20 intact maxillary central incisors were collected according to the parameters described by Wheeler [5].

For each sample, a silicone index (Figure 1a) was created with a dedicated material (Platinum 85, Zhermack S.p.a.) in order to check the thickness of the dental tissue removed during the tooth preparation.

One experienced prosthodontist performed the teeth preparations for PLVs (Figure 1b). According to the preparation geometries, the samples were divided into 2 experimental groups $(n=10)$ called window preparations (WI) and butt joint preparations (BJ).

For window preparations the incisal margin was preserved, while for butt joint preparations (BJ) the incisal margin was removed to a length of $2 \mathrm{~mm}$.

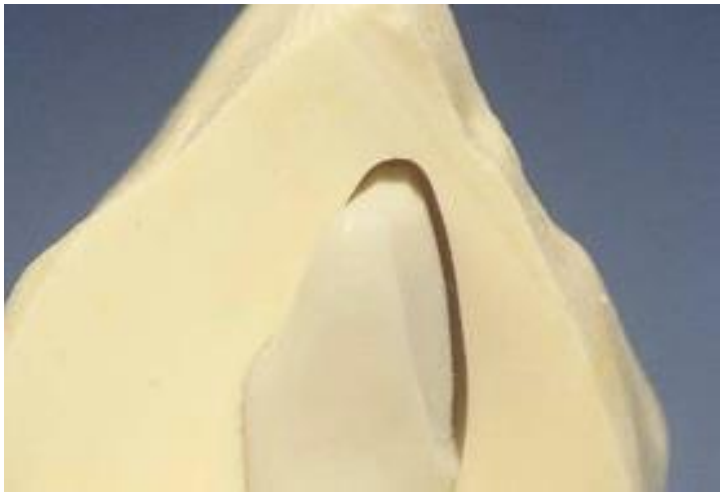

(a)

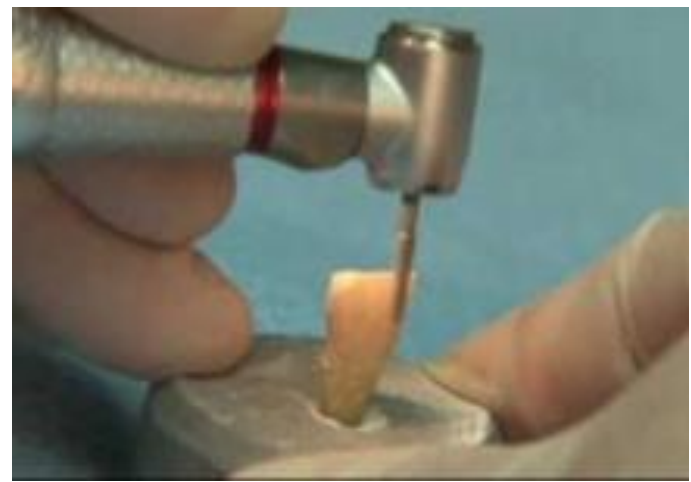

(b)

Figure 1. Specimen preparation: (a) Silicone Index; (b) Tooth preparation by an experienced prosthodontist.

To better discriminate the enamel from the dentine, after tooth preparation, each specimen was immersed in 37.5\% phosphoric acid (Gel Etchant, Kerr Corporation), for $30 \mathrm{~s}$; then, the etched tooth surface was rinsed for $30 \mathrm{~s}$ and finally dried with clean, oil-free, air.

Subsequently, the surfaces were photographed using a stereomicroscope (SOM 82, Karl Kaps) at a magnification of $16 \times$.

A dedicated software (Adobe Photoshop CS4 Extended v11.0, Adobe Inc., San Jose, CA, USA) was used to analyze the pictures taken for each sample. A measurement scale $(1 \mathrm{~mm}=129 \mathrm{px})$ was set.

In order to assess the quantity of exposed dentin, the full prepared area of the tooth was selected with the "Quick Selection Tool" setting a diameter of 3 px and recording the number of pixels from the "Histogram" function after clicking on "click for histogram with uncached data"; then, the same operation was made for the exposed dentin area, in order to obtain the percentage of area corresponding to exposed dentin on the full prepared tooth area, according to the following formula: $($ exposed dentin area $(\mathrm{px})) /($ prepared tooth area $(\mathrm{px})) \times 100=\%$ of exposed dentin area compared to the tooth prepared area.

In addition to descriptive statistics (CI 95\%), a 2-way ANOVA and the Games-Howell test were used to analyze differences among groups $(\alpha=0.05)$. 


\section{Results}

The means of the percentage of dentin exposure were: $\mathrm{WI}=30.48 \%$; $\mathrm{BJ}=30.99 \%$; $\mathrm{ST} / \mathrm{WI}=58.05 \%$; $\mathrm{ME} / \mathrm{WI}=22.82 \% ; \mathrm{EX} / \mathrm{WI}=10.55 \% ; \mathrm{ST} / \mathrm{BJ}=40.56 \% ; \mathrm{ME} / \mathrm{BJ}=28.99 \% ; \mathrm{EX} / \mathrm{BJ}=23.42 \%$.

The 2-way ANOVA detected significant differences among operators $(p<0.001)$ but not between WI and BJ $(p=0.898)$.

The Games-Howell test detected differences between ST/WI and ME/WI $(p=0.005)$ and between $\mathrm{ME} / \mathrm{WI}$ and EX/WI $(p<0.001)$.

\section{Discussion}

As can be seen from the results of the present study, the average values of exposed dentin found in the 2 different preparation geometries, window and butt joint, are similar and equal to about $30 \%$; so, they fall within the ideal range of enamel preservation $(50-70 \%)$ in order to achieve optimal adhesion [6].

Considering the different preparation geometries as statistical variables and since no statistically significant differences were detected between the 2 experimental groups, the first null hypothesis according to which there is no association between the type of preparation of the tooth and the quantity of exposed dentin was accepted. Furthermore, considering the evaluations of the different operators as study variables and having statistically significant differences detected between these 3 experimental groups, the second null hypothesis according to which there is no difference between the clinical experience of the operators in the visualization of the hard tissues of the tooth was rejected.

As evidenced by the results of the present study, there is a high intra- and inter-individual variability in the discrimination of the tooth hard tissues and therefore in the visualization of the exposed dentin. This data is independent from the evaluator's clinical experience. In order to limit this variability as much as possible and therefore to standardize the preparation procedures, the use of magnification systems can be a valuable aid.

\section{Conclusions}

There is no difference in the detection of exposed dentine among operators with different expertise for BJ preparation, whereas differences were detected between ME and the other 2 operators in the WI preparation. Moreover, the quantity of exposed dentin is not related to different tooth preparation geometry.

Author Contributions: Conceptualization, G.R.; methodology, R.S.; validation, F.Z.; formal analysis, F.Z.; investigation, G.R.; resources, G.R.; data curation, R.S.; writing-original draft preparation, F.Z. and G.R.; writing-review and editing, F.Z. and R.S. All authors have read and agreed to the published version of the manuscript.

Funding: This research received no external funding.

Conflicts of Interest: The authors declare no conflict of interest.

\section{References}

1. Hickey, J.C.; Boucher, C.O.; Hughes, G.A. The Glossary of Prosthodontic Terms: Ninth Edition. J. Prosthet. Dent. 2017, 117, e1-e105.

2. Shetty, A.; Kaiwar, A.; Shubhashini, N.; Ashwini, P., Naveen, D.N., Adarsha, M.S., Shetty, M.; Meena, N. Survival rates of porcelain laminate restoration based on different incisal preparation designs: An analysis. J. Conserv. Dent. 2011, 14, 10-15.

3. Chai, S.Y.; Bennani, V.; Aarts, J.M.; Lyons, K. Incisal preparation design for ceramic veneers: A critical review. J. Am. Dent. Assoc. 2018, 149, 25-37.

4. Albanesi, R.B.; Pigozzo, M.N.; Sesma, N.; Laganá, D.C.; Morimoto, S. Incisal coverage or not in ceramic laminate veneers: A systematic review and meta-analysis. J. Dent. 2016, 52, 1-7.

5. Wheeler, R.C. Tooth Form: A Manual on Drawing and Carving, 1st ed.; W. B. Saunders: Philadelphia, PA, USA, 1939. 
6. Chiche, G.J.; Pinault, A. Esthetics of Anterior Fixed Prosthodontics, 1st ed.; Quintessence: Chicago, IL, USA, 1994; pp. 62-64.

Publisher's Note: MDPI stays neutral with regard to jurisdictional claims in published maps and institutional affiliations.

(C) 2020 by the authors. Submitted for possible open access publication under the terms and conditions of the Creative Commons Attribution (CC BY) license (http://creativecommons.org/licenses/by/4.0/). 